\title{
Targeting JNK as a Novel Approach to Drug Metabolism Regullation
}

Gleb Nikolaevich Zyuz'kov 1,*(i), Olga Sergeevna Bryushinina 1(iD), Yuliya Genad'evna Zyuz'kova 1(D), Alexander Pavlovich Lakeev 1(i), Natalia Yur’evna Abdrashitova 1(i), Galina Andreevna Frelikh 1(i), Daria Vladimirovna Tsuran ${ }^{1}{ }^{(1)}$, Elena Anatol'evna Yanovskaya ${ }^{1}{ }^{(D)}$, Vladimir Vasil'evich Udut ${ }^{1}$ (D)

1 Goldberg Research Institute of Pharmacology and Regenerative Medicine, Tomsk National Research Medical Center, Russian Academy of Sciences, Tomsk, Russia, 3 Lenin Prospect, Tomsk, 634028, Russia; nii@ pharmso.ru;

* Correspondencezgn@pharmso.ru (G.N.Z.);

Received: 26.10.2021; Revised: 15.11.2021; Accepted: 18.11.2021; Published: 25.11.2021

\begin{abstract}
The management of pharmacokinetics and pharmacodynamics of drugs constitutes an approach for personalizing pharmacotherapy. This can be achieved by controlling xenobiotic metabolism. This research aimed to study the possibility of controlling the biotransformation of substances in the body through targeted regulation of intracellular signal transduction. By UPLCMS/MS, the effect of JNK inhibitors on the metabolism of venlafaxine xenobiotic by liver cells was investigated in vitro. The blocking of JNK in hepatic homogenate cells containing the antidepressant was accompanied by an increase in the intensity of its biotransformation. There was a significant increase in forming a single pharmacologically active metabolite of O-desmethylvenlafaxine in the cell suspension and its further chemical conversion. Data from experiments indicate marked induction of venlafaxine metabolism by the JNK inhibitor. These properties of JNK inhibitors can be used to develop a novel approach to the characterization of antidepressant treatment. Also, the results indicate the prospect of studying activity modifiers of intracellular signaling molecules (in particular, mitogenactivated protein kinases) to develop methods of controlling the process of xenobiotic transformation and create a novel class of pharmaceuticals - targeted drug metabolism regulators.
\end{abstract}

Keywords: metabolism of xenobiotics; drugs; intracellular signal transduction; signaling molecules; JNK; P450.

(C) 2021 by the authors. This article is an open-access article distributed under the terms and conditions of the Creative Commons Attribution (CC BY) license (https://creativecommons.org/licenses/by/4.0/).

\section{Introduction}

The high prevalence of depressive disorders in the population determines the widespread use of antidepressants, including venlafaxine, in the medical practice [1,2]. This drug (which is the racemate of $\mathrm{R}$ - and S-enantiomers) is one of the most effective modern antidepressants, the therapeutic effect of which is realized by blocking the reuptake of serotonin noradrenaline and dopamine [3,4]. However, the insufficient effectiveness of its use in some cases and the side effects encountered [5-9] make it relevant to develop personalized approaches to venlafaxine therapy, including modifying pharmacokinetics and pharmacodynamics $[10,11]$.

The introduction of pharmacological substances into the body is accompanied by a complex process of their interaction with the body's tissues, participation in chemical reactions, and often pronounced modification by metabolizing systems [10-12]. Biotransformation of xenobiotics can occur with the participation of various enzymes. However, most frequently, 
metabolism is performed in liver cells using cytochrome P450 [10,13]. P450 has many functionally different isoforms capable of causing fundamentally different changes to the target substances. In particular, venlafaxine is metabolized with the isoenzyme CYP2D6 to a single pharmacologically active metabolite of O-desmethylvenlafaxine (O-DVLF) [14,15]. In addition, the blood content of this compound is a prognostic criterion that determines the effectiveness of venlafaxine treatment (despite his self-reported antidepressant activity) $[15,16]$.

In turn, all cell functions are known to be realized involving the intracellular signaling transduction system [17-19]. However, the role of individual signaling molecules, including mito-genactivated protein kinase JNK (c-Jun N-terminal kinase) [20], in regulating the xenobiotic-metabolizing function of relevant cells has not yet been studied. At the same time, JNK activity modifiers have recently been actively investigated for their pharmacological properties. Neuroprotective, anti-inflammatory, hemopoietic, and other effects were revealed [21-23]. The discovery of the ability to control the intensity and types of the transformation of the substances in the body by targeted regulation of intracellular signal transduction (including JNK-pathway) can serve as the basis for the development of a novel approach to the modulation of pharmacokinetics and pharmacodynamics of drugs and the creation of personalized pharmacotherapy technologies.

The work aimed to investigate the possibility of controlling the biotransformation of venlafaxine by targeted regulation of intracellular signal transduction in hepatic cells using the JNK inhibitor.

\section{Materials and Methods}

\subsection{Chemicals and drugs.}

Venlafaxine (Aarti Industries, India); IQ-1S (11H-Indeno1,2-bquinoxalin-11-one oxime sodium) (Montana State University, Bozeman, Montana, USA); heparin (Biochemie, Austria); insulin (Actrapid HM, Novo Nordisk, Denmark); analytical standards of venlafaxine hydrochloride and O-desmethylvenlafaxine (Alsachim, France); DMEM; fetal bovine serum (FBS); L-glutamine; dimethyl sulfoxide; ammonium formate; formic acid; acetonitrile; ethyl acetate; ammonia solution; trypan blue (all manufactured by Sigma-Aldrich, USA).

\subsection{Animals and experimental design.}

All animal experiments were carried out following the U.K. Animals (Scientific Procedures) Act, 1986 and associated guidelines, EU Directive 2010/63/EU for animal experiments. The study was approved by the Institute's local Ethics Committee. Experiments were carried out on C57B1/6 mice ( $n=26)$ at the age of 2-2.5 months, weighing 20-22 $\mathrm{g}$. Animals of the 1st category (conventional mice) were obtained from the Experimental Biological Models Department of Goldberg Research Institute of Pharmacology and Regenerative Medicine (Tomsk, Russia) (certificate available). The animals were removed from the experiment (sacrificed) using $\mathrm{CO}_{2}$ cameras.

As the xenobiotic-metabolizing test system, mouse hepatic homogenate was used. The JNK inhibitor IQ-1S was added to the cell suspension in vitro. Its final concentration was $5 \mu \mathrm{M}$ and $15 \mu \mathrm{M}$. After $30 \mathrm{~min}$, venlafaxine at a dose of $150 \mathrm{ng} / \mathrm{ml}$ was added to the homogenate. Then, after $30 \mathrm{~min}, 1,2,4$, and $24 \mathrm{~h}$ in tissue culture, the content of venlafaxine (VLF), and its 
main metabolite O-desmethylvenlafaxine (O-DVLF) was determined [5,24]. The control was a hepatic homogenate containing an equivalent amount of venlafaxine and a JNK inhibitory solvent (dimethyl sulfide, final concentration $0.15 \%$ ).

\subsection{Tissue homogenization and incubation.}

The liver of the experimental animals was dissociated with a glass tissue homogenizer in a culture medium of the following composition: 70\% DMEM, 30\% fetal calf serum, 280 $\mathrm{ng} / \mathrm{ml} \mathrm{L-glutamine,} 5 \mathrm{IU} / \mathrm{ml}$ heparin, $5 \mu \mathrm{g} / \mathrm{ml}$ insulin. The resulting homogenate was filtered (30 $\mu \mathrm{m}$ filter, Miltenyi Biotec, Germany), washed twice by centrifugation (1000 rpm for 10 $\mathrm{min}$ ), and evaluated viability for cells with trypan blue. The cell concentration was adjusted to $8 \times 10^{7} / \mathrm{ml}$ (viable cells) and incubated in thermo-shaker TS-100 (Biosan, Latvia) at $37^{\circ} \mathrm{C}$.

\subsection{Identifying $V L F$ and $O-D V L F$}

\subsubsection{Sample preparation.}

The sample preparation method was based on the principle of liquid-liquid extraction with ethyl acetate of the target component from the biological test matrix. In $2 \mathrm{ml}$ Eppendorf tubes, $200 \mu \mathrm{l}$ of the prepared homogenate was placed, $30 \mu \mathrm{l}$ of $25 \%$ ammonia solution and $1000 \mu \mathrm{l}$ of ethyl acetate were added, stirred on a vortex shaker at $2500 \mathrm{rpm}$ for $5 \mathrm{~min}$. The tubes were then centrifuged at 10,000 rpm for $5 \mathrm{~min}$, the upper fraction was collected in a volume of $650 \mu$, placed in a vial, and chromatographic analysis was performed.

\subsubsection{UPLC-MS/MS analysis.}

The VLF and O-DVLF detection was conducted by high-performance liquid tandem mass spectrometry (HPLC-MS/MS) $[15,25]$ based on a Nexera XR liquid chromatograph (Shimadzu, Japan) with the Nucleodur C18 Gravity column $(50 \times 2.0 \mathrm{~mm}, 3 \mu \mathrm{m}, 100 \AA)$ (Macherey-Nagel, Germany) and the AB Sciex QTrap 3200 tandem mass spectrometer (AB Sciex, USA). The software Analyst 1.6 and MultiQuant 2.1 were used to collect and process chromatography data, respectively.

The analytes were identified in MRM (multiple reaction monitoring) modes. The value of $\mathrm{m} / \mathrm{z}$ for the VLF ion (parent ion) is 278.09 , the value of $\mathrm{m} / \mathrm{z}$ for the basic ion product is 58 . The value of $\mathrm{m} / \mathrm{z}$ for the ion O-DVLF (parent ion) is 264.1 , the value of $\mathrm{m} / \mathrm{z}$ for the basic ion product is 57.9. The chromatographic analysis was performed in isocratic mode. The composition of the moving phase is acetonitrile (eluent B) and an aqueous solution of $5 \mathrm{~mm}$ ammonium format with the addition of $0.1 \%$ formic acid (eluent $A$ ) in a ratio of 80:20. The flow rate was $0.30 \mathrm{ml} / \mathrm{min}$ - injection volume $1 \mu \mathrm{l}$. The column was thermostated at $40^{\circ} \mathrm{C}$. Average venlafaxine retention time $1 \mathrm{~min}, \mathrm{O}-\mathrm{DVLF}$ - $0.85 \mathrm{~min}$. Total chromatography time was 2 min. Quantitative analysis was carried out by absolute calibration by constructing a calibration relationship in the coordinates "nominal concentration of analyte - peak area" using the software package MultiQuant 2.1. The chromatographic peak area (arbitrary unit) and concentration $(\mathrm{C}, \mathrm{ng} / \mathrm{ml}) \mathrm{VLF}$ and O-DVLF.

\subsection{Statistical analysis.}

Data were obtained in three series of experiments. Two measurements were taken each time. The results were processed by variation statistics using the STATISTICA 6.0 assay 
package using the non-parametric Mann-Whitney U test. The values are presented in the form of mean arithmetic and standard error of the mean $(M \pm S E M)$, the reliability of the differences between the groups was noted at $\mathrm{p}<0.05[26]$.

\section{Results and Discussion}

\subsection{Method validation.}

The UPLC-MS/MS method used to quantify VLF and O-DVLF was tested. After its optimization, the appropriate calibration curves were constructed. They demonstrated perfect linearity in the range of $10.0-6000 \mathrm{ng} / \mathrm{mL}$ (at nine concentration levels of calibration solutions). The correlation coefficients $(r)$ for VLF and O-DVLF were 0.99928 and 0.99918 , respectively (typical equation: VLF: $\mathrm{y}=453.821 \mathrm{x}-435.833$; O-DVLF: $\mathrm{y}=25.908 \mathrm{x}-24.132$ ) (Fig. 1).

Chromatograms of blank samples contained low-intensity peaks at the time of analyte retention. However, their signal was $<20 \%$ of the response of the analyte at the "lower limit of quantification" $(0.5 \mathrm{ng} / \mathrm{ml})$, which indicated that there was no effect of endogenous components of the biological matrix under study (test system) on the area of VLF and ODVLF peaks.
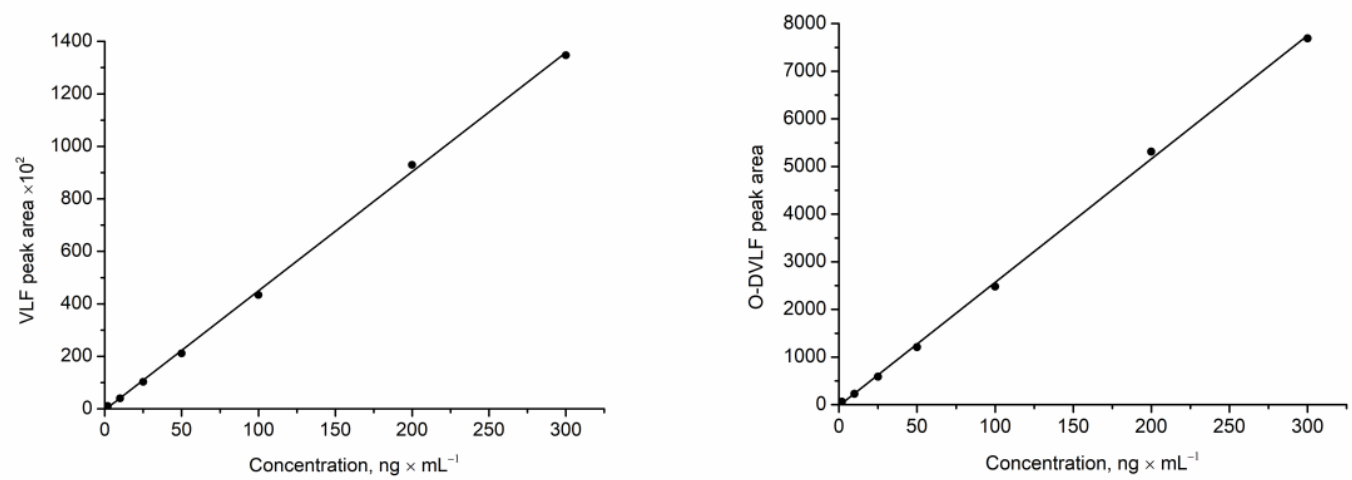

Figure 1. VLF and O-DVLF calibration curves in the hepatic homogenate of C57B1/6 mice.

\subsection{VLF analysis.}

The addition of VLF (150 ng/ml) to hepatic homogenate was accompanied by an expected decrease in its concentration during the experiment. Calculation of the chromatography data (Table 1) showed that by $24 \mathrm{~h}$, its content in the cell suspension was $135.99 \pm 3.73 \mathrm{ng} / \mathrm{ml}$ (Figure 2, a). The preliminary introduction of the JNK inhibitor into the test system expressed increased the intensity of xenobiotic metabolism. In both cases $(5 \mu \mathrm{M}$ and $15 \mu \mathrm{M}$ IQ-1S), there was a statistically significant decrease in VLF content at $30 \mathrm{~min}, 1$ and $2 \mathrm{~h}$ after cell culture was added (Figure 2, b). In addition, when IQ-1S was used at a concentration of $15 \mu \mathrm{M}$, the amount of the substance detected after 24 hours was also lower than in control.

Thus, the blockade of JNK was accompanied by induction of venlafaxine metabolism, for the biotransformation of which the enzymes of the P450 family are known to be responsible [13-15]. 
Table 1. Chromatographic analysis of VLF and O-DVLF in the hepatic homogenate of C57B1/6 mice after venlafaxine administration. 1 - without an inhibitor; 2 - with JNK inhibitor $(5 \mu \mathrm{M}), 3$ - with JNK inhibitor $(15$ $\mu \mathrm{M}),(\mathrm{M} \pm \mathrm{SEM})$.

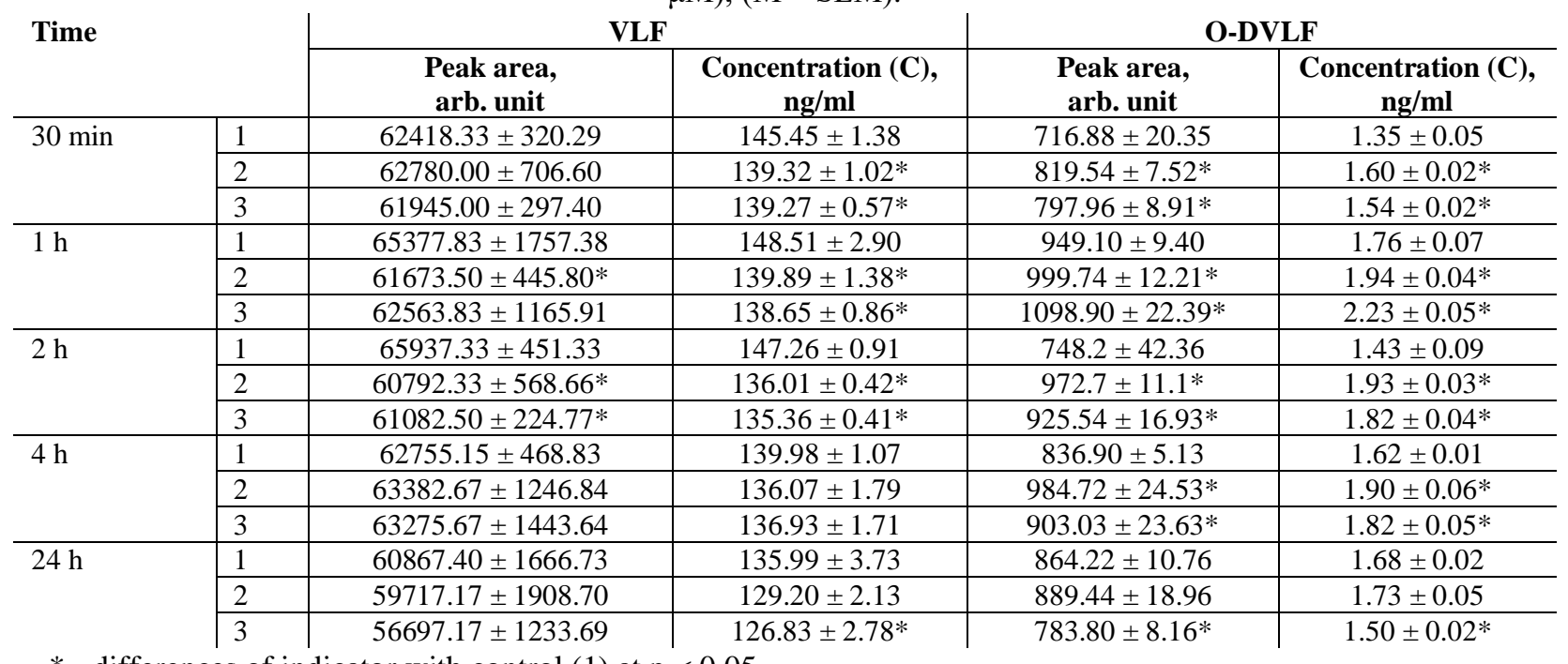

* - differences of indicator with control (1) at $\mathrm{p}<0.05$
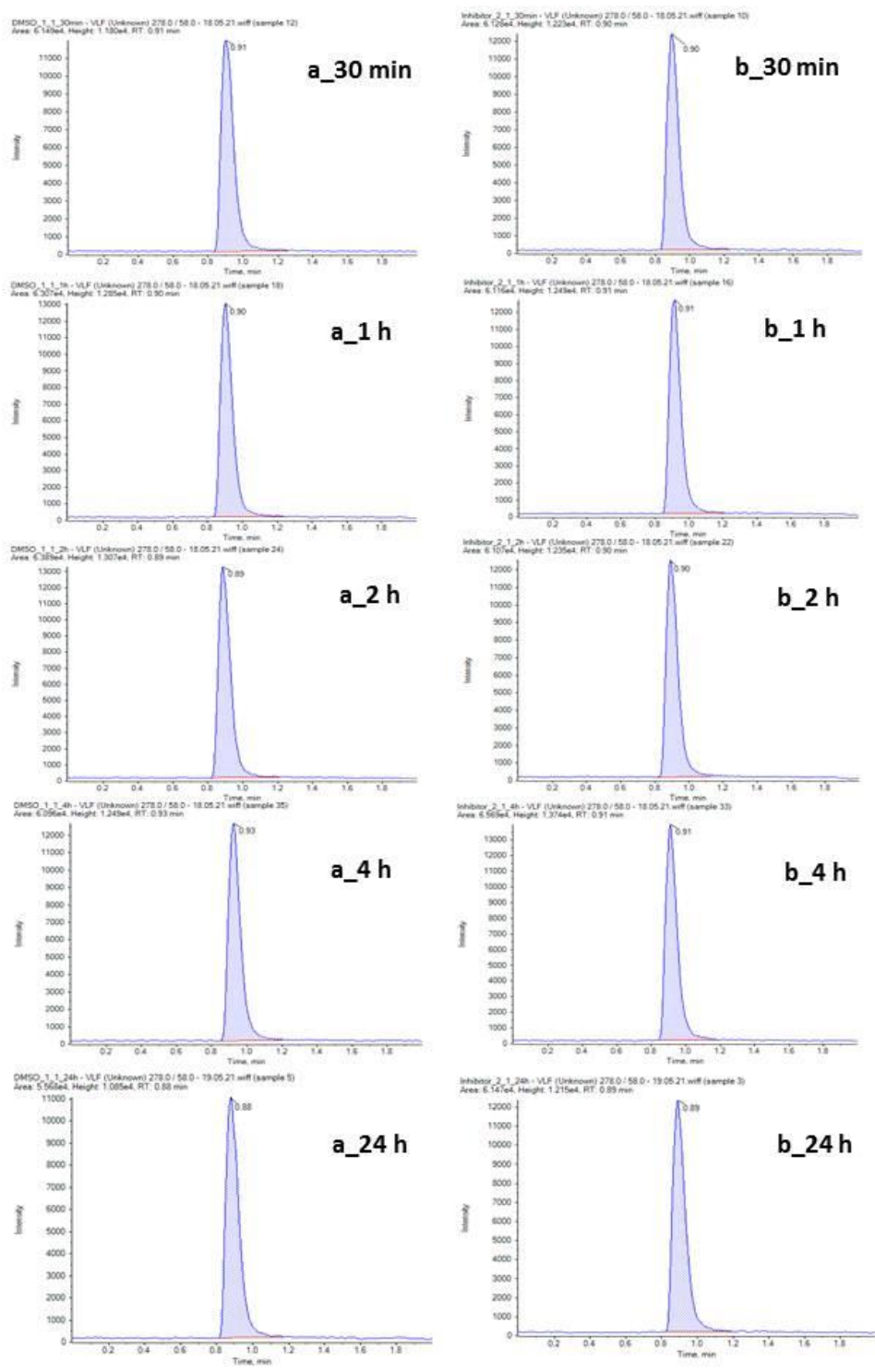

Figure 2. VLF chromatograms $30 \mathrm{~min}, 1,2$, 4, and $24 \mathrm{~h}$ after venlafaxine administration to the hepatic homogenate. Here and in figure 4: $a$ - a suspension of cells without an inhibitor; $b$ - a suspension of JNK inhibitor cells $(15 \mu \mathrm{M})$. 

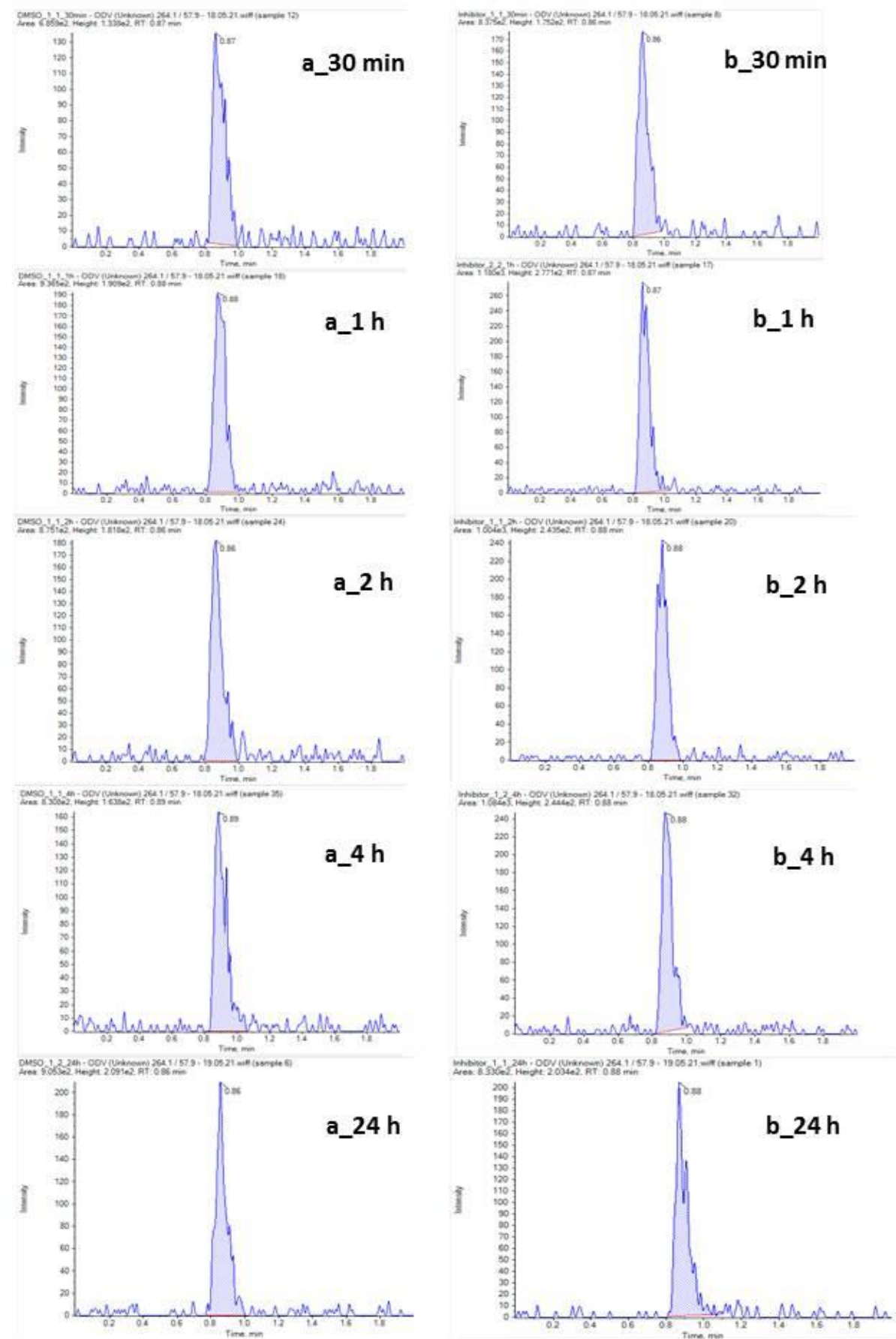

Figure 3. O-DVLF chromatograms $30 \mathrm{~min}, 1,2,4$, and $24 \mathrm{~h}$ after venlafaxine administration to the hepatic homogenate.

\section{3. $O-D V L F$ analysis.}

The introduction of venlafaxine into hepatic homogenate was accompanied by the rapid appearance of O-DVLF in the study material. The metabolite content per 30 min was $1.35 \pm$ $0.05 \mathrm{ng} / \mathrm{ml}$. Subsequently, an increase in the studied parameter was observed. However, the increase in the concentration of O-desmethylvenlafaxine was not linear. Analysis of chromatographic data (Table 1) indicated that the value reached a maximum of 1 hour after the antidepressant was added to the cell suspension $(1.76 \pm 0.07 \mathrm{ng} / \mathrm{ml})$. When it was determined for $2 \mathrm{~h}$, some decrease of O-DVLF content in liver homogenate was recorded, indicating the further transformation of O-desmethylvenlafaxine with the formation of $\mathrm{N}$ desmethylvenlafaxine and/or other inactive metabolites of the initial compound by this term 
$[14,15]$. At the same time, an increase in the concentration of O-DVLF was observed at 4 and $24 \mathrm{~h}$ of the study, comparable in level with that at $1 \mathrm{~h}$ after the introduction of venlafaxine into the hepatic homogenate (Table 1; Figure 3, a).

Thus, the dynamics of the level of O-DVLF content in the test system reflected not only the intensity of its formation but also the nature of further transformations of $\mathrm{O}$ desmethylvenlafaxine.

The addition of the JNK inhibitor to the culture medium had a pronounced effect on the biotransformation of the xenobiotic under study. Regardless of the protein kinase blocker dose used, a significant acceleration of venlafaxine metabolism and an increase in O-DVLF content in the hepatic homogenate were recorded. The concentration of O-DVLF was $118.5 \%, 110.2 \%$, $135.0 \%, 117.3 \%$, and $114.1 \%, 126.7 \%, 127.3 \%, 112.3 \%$ by $30 \mathrm{~min}, 1,2,4 \mathrm{~h}$ with $5 \mu \mathrm{M}$ and $15 \mu \mathrm{M}$ "IQ-1S," respectively (Table 1; Figure 3, b). The parameter under study reached the highest value after $1 \mathrm{~h}$ when introducing the JNK inhibitor $(2.23 \pm 0.05 \mathrm{ng} / \mathrm{ml})$ into the cell test system. At the same time, its value by $30 \mathrm{~min}, 2$, and $4 \mathrm{~h}$ was higher using a $5 \mu \mathrm{M}$ activity modifier of this MAP kinase. The absence of unambiguous regularity in the change in chromatographic analysis data (Table 1) reflecting the content of O-DVLF in the cell suspension when using different concentrations of the JNK inhibitor confirms the complex transformations and conversions of venlafaxine and O-DVLF [15,27] in the test system used under the influence of probably different metabolizing systems (primarily different isoforms P450 [10,13]). Moreover, $15 \mu \mathrm{M}$ of the JNK inhibitor caused a more intense metabolism of the antidepressant. The smaller values of the detectable O-desmethylvenlafaxine by $30 \mathrm{~min}, 2,4 \mathrm{~h}$ were probably due to its faster further conversion [3,14]. This was supported by a reduction in O-DVLF concentration in the test system by $24 \mathrm{~h}$ of follow-up using a $15 \mu \mathrm{M}$ JNK inhibitor (up to $89.3 \%$ from the control value).

The findings suggest the involvement of the JNK-mediated pathway $[18,22,23]$ in the regulation of metabolizing xenobiotics of liver cell function. In particular, the role of this secondary messenger concerning the transformation of one of the most effective antidepressants - venlafaxine [24,27], is reduced to the inhibition of the process of its biochemical modifications. The results of experiments indicate the induction of the metabolism of this drug under the influence of the JNK inhibitor (Figure 4).

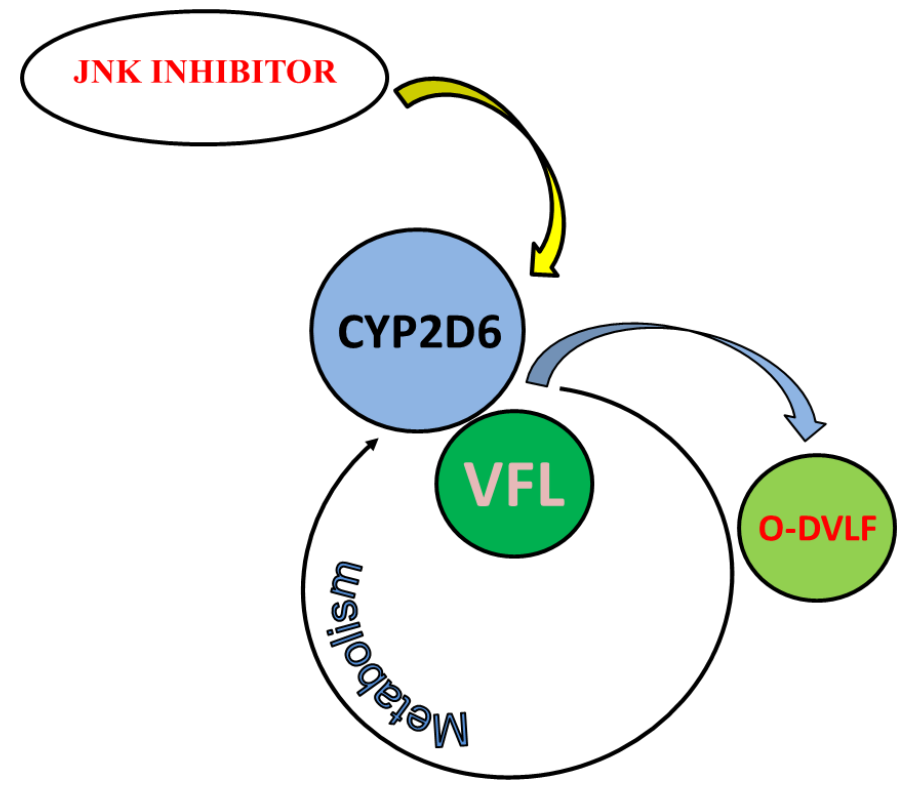

Figure 4. Mechanism of induction of venlafaxin metabolism with the JNK inhibitor. 
The mechanism of the detected action of the protein kinase blocker is its participation in the regulation of the activity of not only the isoenzyme CYP2D6 (responsible for the formation of O-desmethylvenlafaxine), but also CYP2C19, CYP3A4, and CYP2C9 (the functioning of which is accompanied by the appearance, first of all, of inactive metabolites $\mathrm{N}$, O-diosmethylvenlafaxine and their glucuronide conjugates) [3, 14]. The discovered properties of the JNK inhibitor can be used to develop a fundamentally novel approach to personification and increase the effectiveness of antidepressant therapy with venlafaxine [15,16,24,28]. Based on the revealed phenomena, the inactivation of JNK in liver cells can increase the level of drug transformation intensity in "weak metabolisants" (persons with a low level of CYP2D6 expression, or in patients with liver diseases $[4,5,14]$ ) to that normal to such in the norm (“extensive metabolisants" of venlafaxine).

\section{Conclusions}

The experimental data indicate pronounced drug metabolism-inducing properties of the JNK inhibitor. These protein kinase activity modifier effects can be used to develop personalized approaches to venlafaxine antidepressant therapy. Also, the fundamental possibility of controlling the metabolism of pharmacological substances by modifying the activity of intracellular signaling molecules can serve as the basis for the creation of a novel class of pharmaceuticals - "targeted regulators of xenobiotics metabolism".

\section{Funding}

The studies were carried out as part of the execution of the State task of the Ministry of Science and Higher Education of Russia on the topics No. 0550-2019-0011, No. 0550-2019-0012, and No. FGWM-2022-0018.

\section{Acknowledgments}

We thank the Director of the Goldberg Research Institute of Pharmacology and Regenerative Medicine V.V. Zhdanov, for providing research infrastructure for the work.

\section{Conflicts of Interest}

The authors declare no conflict of interest.

\section{References}

1. Jakobsen, J.C.; Gluud, C.; Kirsch, I. Should antidepressants be used for major depressive disorder? BMJ Evid. Based. Med. 2020, 25, https://doi.org/10.1136/bmjebm-2019-111238.

2. Alcántara Montero, A.; González Curado, A. Is there scientific evidence for the use of venlafaxine to treat neuropathic pain? Neurologia (Engl Ed) 2020, 35, 522-530, https://doi.org/10.1016/j.nrl.2018.07.006.

3. Tozatto, E.; Benzi, J.R.L.; Rocha, A.; Coelho, E.B.; Lanchote, V.L. Nifedipine Does Not Alter the Pharmacokinetics of Venlafaxine Enantiomers in Healthy Subjects Phenotyped for CYP2D6, CYP2C19, and CYP3A. J. Clin. Pharmacol. 2021, 61, 319-327, https://doi.org/10.1002/jcph.1745.

4. Jessel, C.D.; Mostafa, S.; Potiriadis, M.; Everall, I.P.; Gunn, J.M.; Bousman, C.A. Use of antidepressants with pharmacogenetic prescribing guidelines in a 10-year depression cohort of adult primary care patients. Pharmacogenet. Genomics. 2020, 30, 145-152, https://doi.org/10.1097/FPC.0000000000000406.

5. Sasaki, T.; Yasui-Furukori, N.; Komahashi-Sasaki, H.; Shinozaki, M.; Hayashi, Y.; Kato, K.; Inoue, Y.; Tsuchimine, S.; Watanabe, T.; Sugawara, N.; Shimoda, K. CYP2D6*10 polymorphism and the enantioselective O-desmethylation of S-(+)- and R-(-)-venlafaxine in Japanese psychiatric patients. Basic Clin. Pharmacol. Toxicol. 2021, 128, 677-685, https://doi.org/10.1111/bcpt.13560. 
6. Saleem, U.; Zubair, S.; Riaz, A.; Anwar, F.; Ahmad, B. Effect of Venlafaxine, Pramipexole, and Valsartan on Spermatogenesis in Male Rats. ACS Omega, 2020, 5, 20481-20490, https://doi.org/10.1021/acsomega.0c02587.

7. Kobylianskii, J.; Wu, P.E. Venlafaxine-induced hypoglycemia. CMAJ 2021, 193, https://doi.org/10.1503/cmaj.78409.

8. Stahl, S.T.; Jung, C.; Weiner, D.K.; Peciña, M.; Karp, J.F. Opioid Exposure Negatively Affects Antidepressant Response to Venlafaxine in Older Adults with Chronic Low Back Pain and Depression. Pain Med. 2020, 21, 1538-1545, https://doi.org/10.1093/pm/pnz279.

9. Maalouli, W.M.; Hilliard, B.S. Venlafaxine-induced encephalopathy in term newborn. SAGE Open Med. Case Rep. 2020, 8, https://doi.org/10.1177/2050313X20952981.

10. Driscoll, J.P.; Sadlowski, C.M.; Shah, N.R.; Feula, A. Metabolism and Bioactivation: It's Time to Expect the Unexpected. J. Med. Chem. 2020, 63, 6303-6314, https://doi.org/10.1021/acs.jmedchem.0c00026.

11. De Rose, D.U.; Cairoli, S.; Dionisi, M.; Santisi, A.; Massenzi, L.; Goffredo, B.M.; Dionisi-Vici, C.; Dotta, A.; Auriti, C. Therapeutic Drug Monitoring Is a Feasible Tool to Personalize Drug Administration in Neonates Using New Techniques: An Overview on the Pharmacokinetics and Pharmacodynamics in Neonatal Age. Int. J. Mol. Sci. 2020, 21, https://doi.org/10.3390/ijms21165898.

12. Maher, D.; Ailabouni, N.; Mangoni, A.A.; Wiese, M.D.; Reeve E. Alterations in drug disposition in older adults: a focus on geriatric syndromes. Expert Opin. Drug Metab. Toxicol. 2021, 17, 41-52, https://doi.org/10.1080/17425255.2021.1839413.

13. Klomp, S.D.; Manson, M.L.; Guchelaar, H.J.; Swen, J.J. Phenoconversion of Cytochrome P450 Metabolism: A Systematic Review. J. Clin. Med. 2020, 9, https://doi.org/10.3390/jcm9092890.

14. Kuzin, M.; Scharrer, I.; Nolan, D.; Baumgartner, M.; Paulzen, M.; Schoretsanitis, G.; Xepapadakos, F. The role of the poor metabolizer genotype CYP2D6 and CYP1A2 phenotype in the pharmacokinetics of duloxetine and venlafaxine-A case report. Basic Clin. Pharmacol. Toxicol. 2020, 127, 354-357, https://doi.org/10.1111/bcpt.13428.

15. Tozatto, E.; Benzi, J.R.L.; Rocha, A.; Coelho, E.B.; Lanchote, V.L. Nifedipine Does Not Alter the Pharmacokinetics of Venlafaxine Enantiomers in Healthy Subjects Phenotyped for CYP2D6, CYP2C19, and CYP3A. J. Clin. Pharmacol. 2021, 61, 319-327, https://doi.org/10.1002/jcph.1745.

16. Stamm, T.J.; Becker, D.; Sondergeld, L.M.; Wiethoff, K.; Hiemke, C.; O’Malley, G.; Ricken, R.; Bauer, M.; Adli, M. Prediction of antidepressant response to venlafaxine by a combination of early response assessment and therapeutic drug monitoring. Pharmacopsychiatry, 2014, 47, 174-9, https://doi.org/10.1055/s-00341383565.

17. Espinosa-Riquer, Z.P.; Segura-Villalobos, D.; Ramírez-Moreno, I.G.; Pérez Rodríguez, M.J.; Lamas, M.; Gonzalez-Espinosa, C. Signal Transduction Pathways Activated by Innate Immunity in Mast Cells: Translating Sensing of Changes into Specific Responses. Cells, 2020, 9, https://doi.org/10.3390/cells9112411.

18. Zyuz'kov G.N. Targeted Regulation of Intracellular Signal Transduction in Regeneration-Competent Cells: A new Direction for Therapy in Regenerative Medicine. Biointerface Res. Appl. Chem. 2021, 11, 1223812251 .

19. Zyuz'kov, G.N.; Suslov, N.I.; Miroshnichenko, L.A.; Simanina, E.V.; Polyakova, T.Yu.; Stavrova, L.A.; Zhdanov, V.V.; Minakova, M.Y.; Udut, E.V.; Udut, V.V. Halogenated (Cl-ion) songorine is a new original agonist of fibroblast growth factor receptors of neuronal-committed progenitors possessing neuroregenerative effect after cerebral ischemia and hypoxia in experimental animals. Biointerface Res. Appl. Chem. 2019, 9, 4317-4326, https://doi.org/10.33263/BRIAC95.317326.

20. Anfinogenova, N.D.; Quinn, M.T.; Schepetkin, I.A.; Atochin, D.N. Alarmins and c-Jun N-Terminal Kinase (JNK) Signaling in Neuroinflammation. Cells 2020, 9, https://doi.org/10.3390/cells9112350.

21. Zyuz'kov, G.N.; Miroshnichenko, L.A.; Simanina, E.V.; Stavrova, L.A.; Polyakova, T.Yu. Intracellular signaling molecules of nerve tissue progenitors as pharmacological targets for treatment of ethanol-induced neurodegeneration. J. Basic Clin. Physiol. Pharmacol. 2021, https://doi.org/10.1515/JBCPP-2020-0317.

22. Zyuz'kov, G.N.; Suslov, N.I.; Povet'eva, T.N.; Nesterova, Y.V.; Afanas'eva, O.G.; Udut, E.V.; Miroshnichenko, L.A. Simanina, E.V. Polyakova, T.Y.; Stavrova, L.A.; Chaikovskii, A.V.; Kul'pin, P.V.; Udut, V.V.; Dygai, A.M.; Zhdanov, V.V. Psychopharmacological Effects of JNK Inhibitor in Posthypoxic Encephalopathy and Mechanisms of Their Development. Bull. Exp. Biol. Med. 2017, 163, 18-21, https://doi.org/10.1007/s10517-017-3727-9.

23. Zyuz'kov, G.N.; Zhdanov, V.V.; Miroshnichenko, L.A.; Simanina, E.V.; Polyakova, T.Yu.; Stavrova, L.A.; Simanina, E.V.; Agafonov, V.I.; Minakova, M.Yu.; Danilets, M.G.; Ligacheva, A.A. Hemostimulating Effects of c-Jun N-Terminal Kinase (JNK) Inhibitor during Cytostatic Myelosuppression and Mechanisms of Their Development. Bull. Exp. Biol. Med. 2020, 169, 332-337, https://doi.org/10.1007/s10517-020-04880-z.

24. Scherf-Clavel, M.; Hommers, L.; Wurst, C.; Stonawski, S.; Deckert, J.; Domschke, K.; Unterecker, S.; Menke, A. Higher venlafaxine serum concentrations necessary for clinical improvement? Time to re-evaluate the therapeutic reference range of venlafaxine. J. Psychopharmacol. 2020, 34, 1105-1111, https://doi.org/10.1177/0269881120936509. 
25. Zhou, C.; Li, X.; He, A.; Liu, T.; Tian, J.; Jiang, M.; Fan, L. Development of a UPLC-MS/MS Method for the Quantification of VS-5584 and Its Application in Pharmacokinetic Studies in Rats. J. Anal. Methods Chem. 2020, 16, https://doi.org/10.1155/2020/8811522.

26. Curtis, M.J.; Bond, R.A.; Spina, D.; Ahluwalia, A.; Alexander, S.P.; Giembycz, M.A. Experimental design and analysis and theirreporting: new guidance for publication in BJP. Br. J. Pharmacol. 2015, 172, 34613471, https://doi.org/10.1111/bph.12856.

27. Hancu, G.; Lupu, D.; Milan, A.; Budău, M.; Barabás-Hajdu, E. Enantioselective analysis of venlafaxine and its active metabolites: A review on the separation methodologies. Biomed. Chromatogr. 2021, 35, https://doi.org/10.1002/bmc.4874.

28. Zyuz'kov, G.N.; Miroshnichenko, L.A.; Polyakova, T.Yu.; Simanina, E.V.; Stavrova, L.A. Targeting cAMPpathway in Regeneration-Competent Cells of Nervous Tissue: Potential to Create a Novel Drug for Treatment of Ethanol-Induced Neurodegeneration. Cent. Nerv. Syst. Agents Med. Chem. 2021, 21, https://doi.org/10.2174/1871524921666210907102847. 